BACKGROUND: Since the growth state of macrophages in local pathological sites is considered a factor that regulates the processes of many disease, such as tumors, inflammation, and atherosclerosis, the substances that regulate macrophage growth or survival may be useful for disease control. We previously reported that securiosides $A$ and $B$, novel triterpene saponins, exerted macrophage-oriented cytotoxicity in the presence of a L-cell-conditioned medium containing macrophage colony-stimulating factor (M-CSF), while the compounds did not exhibit an effect on macrophages in the absence of the growthstimulating factors.

Aim: This study was undertaken to characterize the growth-inhibitory and the apoptosis-inducing activities of securioside $B$, focusing on the effects of the macrophage-growth factor(s), and to examine the implication of a mitochondria pathway in apoptosis induction.

Methods: The effect of securioside $B$ on a murine macrophage cell line (BAC1.2F5) was examined by MTT assay and lactose dehydrogenase release assay in the presence of L-cell-conditioned medium, M-CSF, or granulocyte-macrophage CSF (GM-CSF).

Results: Securioside $B$ inhibited the growth of the cells stimulated by recombinant M-CSF or GM-CSF, but it scarcely induced cytolysis of the cells under the same conditions. Moreover, securioside $B$ did not induce cell death when the compound only was added to the cells. On the other hand, the compound extensively induced apoptotic cell death in the presence of L-cell-conditioned medium, suggesting that apoptosis induction by securioside $B$ requires the additional factor(s) present in L-cell-conditioned medium. Securioside B plus L-cell-conditioned medium induced the activation of caspase- 3 and caspase9 , but not caspase-8. In addition, cytochrome $c$ release from the mitochondria into the cytosol, and disrupted mitochondria membrane potential, was also observed in the apoptotic BAC1.2F5 cells.

Conclusion: These data suggest that securioside $B$ has growth-inhibitory activity against growth factor-stimulated macrophages, and that it induces apoptotic macrophage death through the activation of a mitochondrial pathway in the presence of L-cellconditioned medium.

Key words: Macrophages, Growth inhibition, Apoptosis, Securioside B, BAC1.2F5 cells, L-cell-conditioned medium, M-CSF, GM-CSF

\section{Characterization of the growth- inhibitory and apoptosis-inducing activities of a triterpene saponin, securioside $B$ against BAC1.2F5 macrophages}

\author{
Satoru Yui ${ }^{1, C A}$, Tomoya Kudo ${ }^{1}$, Kazumi Hodono ${ }^{1}$, \\ Yoshihiro Mimaki ${ }^{2}$, Minpei Kuroda ${ }^{2}$, \\ Yutaka Sashida ${ }^{2}$ and Masatoshi Yamazaki ${ }^{1}$
}

${ }^{1}$ Faculty of Pharmaceutical Sciences, Teikyo University, 1091-1 Sagamiko, Tsukui-gun, Kanagawa 199-0195, Japan; ${ }^{2}$ Laboratory of Medicinal Plant Science, School of Pharmacy, Tokyo University of Pharmacy and Life Science, Horinouchi, Hachioji, Tokyo, Japan

\footnotetext{
${ }^{\mathrm{CA}}$ Corresponding author

Tel: + 81426853736

Fax: + 81426852574

E-mail: sat-yui@pharm.teikyo-u.ac.jp
}

\section{Introduction}

Macrophages play roles in regulating the pathological processes of many diseases, such as tumors, inflammatory diseases, and atherosclerosis, through the production of various cytokines, enzymes, and reactive oxygen intermediates. ${ }^{1,2}$ There are cumulative observations that the local proliferation of macrophages occurs in tumors, ${ }^{3,4}$ atherosclerotic lesions, ${ }^{5-8}$ and inflammatory sites, ${ }^{9,10}$ to expand macrophage accumulation, and the proliferation is thought to influence each pathological process.

The growth of peripheral macrophages is induced by protein factors, macrophage colony-stimulating factor (M-CSF/CSF-1), and granulocyte-macrophage colony-stimulating factor (GM-CSF). ${ }^{11-13}$ We reported that phagocytosed materials by macrophages, such as effete cells, denatured lipoproteins, and 
ligands of scavenger receptors, induce macrophage growth in the mediation of GM-CSF production by macrophages themselves. ${ }^{14-17} \mathrm{M}-\mathrm{CSF} / \mathrm{CSF}-1$ and GMCSF may affect the disease process by modulating macrophage function in addition to inducing growth. CSF-1 expression in tumors reportedly promotes the metastatic character of the tumor cells, possibly by functionally altered macrophages. ${ }^{18}$

Both the local accumulation of macrophages in the local pathological sites and their activation states are considered to influence the regulatory activity of this cell type. In other words, the quantitative aspect of macrophages is important for the regulatory function, as well as the qualitative aspect of macrophages; namely, their activation state or cytokine-producing activity. Accordingly, to find substances that have growth-inhibiting or apoptosis-inducing activity towards macrophages stimulated by macrophage growth factors, may be useful for the regulation of many diseases.

Several substances, such as liposome-encapsulated bisphosphonate clodronate, were developed for the depletion of macrophages. ${ }^{19}$ However, the effect of this drug is thought to be non-specific to macrophages with various growth and activation states: the inhibiting substances or apoptosis-inducing substances oriented to macrophages, stimulated by macrophage growth factors, are needed for a more subtle suppression of macrophages.

We previously reported that triterpene saponins, securiosides A and B, purified from the extract of Securidaca inappendiculata, showed growth-inhibiting and apoptosis-inducing activity against murine inflammatory macrophages in the presence of L-cellconditioned medium, ${ }^{20,21}$ which is a source of MCSF. ${ }^{11}$ The structural difference between securiosides $\mathrm{A}$ and $\mathrm{B}$ is within their sugar chains. ${ }^{20}$ The compounds did not interfere with the growth of other cell types, such as EL-4 lymphoma and L-929 fibrosarcoma cells, at the same concentration that they exerted growth inhibitory and cytotoxic activity against the cultured macrophages. Moreover, the compounds did not alter the viability of the macrophages in the absence of L-cell-conditioned medium and a macrophage-like cell line (J774.1), suggesting that they act preferably on macrophages stimulated by M-CSF or other factors existing in L-cell-conditioned medium. ${ }^{21}$ Although we preliminarily observed that securiosides showed cytotoxicity against macrophages with M-CSF in an MTT assay, ${ }^{21}$ it is still unknown whether the compounds induce not only growth inhibition, but also apoptosis against macrophages treated with M-CSF or another macrophage growth factor, GM-CSF. Accordingly, a more precise study is required to characterize the growth-inhibiting and cytotoxic activity of securiosides in respect to the effect of macrophage growth factors. Also, the intracellular pathways in apoptosis induction by securiosides have not been explored.

In the present paper, we study the requirement of macrophage growth factors for securiosides to induce macrophage apoptosis, and explored the intracellular mechanism of apoptosis induction, using BAC1.2F5 cells, a M-CSF-dependent macrophage cell line. We used only securioside $\mathrm{B}$ for this analysis, since the two securiosides have almost an equal activity for macrophages cultured with L-cell-conditioned medium. $^{20,21}$ The results show that securioside B exhibited a growth-inhibitory effect on the BAC1.2F5 cells in the presence of M-CSF or GM-CSF, but induced apoptosis of the cells in the presence of L-cellconditioned medium, and that the compound activated a mitochondria pathway in the induction of macrophage apoptosis.

\section{Materials and methods}

\section{Reagents}

Recombinant mouse M-CSF (rM-CSF) and recombinant mouse GM-CSF (rGM-CSF) were purchased from Genzyme (Cambridge, MA, USA). Anti-caspase-3 (H-277, rabbit polyclonal) and anti-cytochrome $c$ (H-104, rabbit polyclonal) antibodies were purchased from Santa Cruz Biotechnology (Santa Cruz, CA, USA). Anti-caspase-8 (rabbit polyclonal) was purchased from Calbiochem-Novabiochem Corp. (San Diego, CA, USA). Anti-rabbit immunoglobulin (Ig)G-horseradish peroxidase (HRP) conjugate (goat polyclonal) was from Santa Cruz. A caspase-family inhibitor, Z-VAD-FMK, was purchased from Promega (Madison, WI, USA).

\section{Securioside B}

Securioside B was purified from the hot water extracts of the dried roots of $S$. inappendiculata Hassk as previously described. ${ }^{20,21}$

\section{Macrophages and cell counting}

The BAC1.2F5 mouse macrophage cell line ${ }^{22}$ was kindly supplied by Dr E. R. Stanley (Albert Einstein College of Medicine, New York) and was maintained in RPMI 1640 medium (Nissui Seiyaku Co., Tokyo, Japan), supplemented with 10\% heated-inactivated fetal calf serum (FCS) (Iwaki, Chiba, Japan), $100 \mathrm{U} / \mathrm{ml}$ penicillin, $60 \mu \mathrm{g} / \mathrm{ml} \mathrm{Kanamycin}$, in the presence of $20 \%$ L-cell-conditioned medium, as a source of CSF1. ${ }^{11}$ For the cytotoxicity assay for securioside B, BAC1.2F5 cells in the exponential growth phase were harvested by scraping with a rubber policeman, and the cells were added to the wells of flat-bottomed plates with RPMI 1640 medium, supplemented with 
5\% FCS and the antibiotics (hereafter known as 'medium'). L-cell-conditioned medium, M-CSF, or GM-CSF were simultaneously added with securioside B. The plates were cultured at $37^{\circ} \mathrm{C}$ in a humidified atmosphere of $5 \% \mathrm{CO}_{2}$ until the cytotoxicity was evaluated, as described later. Growth of the BAC1.2F5 cells was evaluated by cell counting. The cells were incubated in 24-well plates (Iwaki) at $1 \times$ $10^{5}$ cells/well in $1 \mathrm{ml}$ medium, and the numbers of adherent cells within five standard-sized areas $(0.25$ $\mathrm{mm}^{2}$ ) in each of two wells were counted.

Mouse peritoneal macrophages were obtained 4 days after an intraperitoneal injection of $30 \mathrm{mg}$ starch into each C3H/He mouse (Japan SLC, Inc., Shizuoka, Japan), and cultured as previously described. ${ }^{21}$

\section{Cytotoxicity assay}

The cytotoxicity of securioside $\mathrm{B}$ towards the BAC1.2F5 cells was evaluated by MTT assay. ${ }^{23}$ The cells were incubated in 96-well microplates (Iwaki) at $1 \times 10^{4}$ cells/well. In the MTT assay, after the indicated culture periods, $25 \mu$ 3-(4,5-dimethyl-2thiazolyl)-2,5-diphenyl-2H-tetrazolium bromide (MTT) $(5 \mathrm{mg} / \mathrm{ml})$ was added to each well, and the plates were incubated for an additional $3 \mathrm{~h}$. Then, 150 $\mu \mathrm{l}$ supernatant was discarded, $100 \mu \mathrm{l}$ acid-isopropanol solution $(0.04 \mathrm{~N} \mathrm{HCl}$ in 2-propanol) was added to each well, and the optical density (588 nm) was measured with a microplate reader (MTP-100; Corona Electric, Ibaragi, Japan). Cytolytic activity was assessed by a L-lactate dehydrogenase (LDH) release assay, and LDH activity in the culture supernatants, which were released from the cytosol of the damaged cells, was measured using a CytoTox 96 Non-radioactive cytotoxicity assay kit (Promega). LDH activity in each residual cell was measured after solubilizing the adherent cells with the solubilizing buffer from the kit. Percent LDH release was calculated as follows: $\% \mathrm{LDH}$ release

$\begin{aligned}= & \frac{\mathrm{LDH} \text { in supernatants }}{\mathrm{LDH} \text { in supernatants }+\mathrm{LDH} \text { in residual cells }} \\ & \times 100\end{aligned}$

Experiments were performed with triplicate determinations in these assays.

\section{DNA breaks}

DNA breaks in the cultured BAC1.2F5 cells were detected in situ by the terminal deoxynucleotidyl transferase (TdT)-mediated dUTP nick end labeling (TUNEL) method, which was originally described by Gavrieli et al. ${ }^{24}$ The BAC1.2F5 cells $\left(2.4 \times 10^{4}\right.$ cells $)$ were cultured in eight-well Lab-Tek slide chambers (Nalge Nunc International, Naperville, IL, USA) with the indicated concentrations of L-cell-conditioned medium and securioside $\mathrm{B}$ for 3 days. After the damaged cells detached from the culture substrate were removed by gentle washing with phosphatebuffered saline (PBS) three times, the DNA breaks in the adherent cells were detected by MEBSTEIN Apoptosis Kit Direct (Medical and Biological Laboratories Co., Ltd., Nagoya, Japan). The TUNEL reaction enzymatically labeled free 3 '-OH termini of the DNA strand breaks with fluorescein-dUTP with TdT. The fluorescein incorporated into the cells was observed by fluorescence microscopy.

\section{Measurement of caspase activity}

The caspase- 3 , caspase- 8 , and caspase- 9 activities in the cytosolic extracts of the BAC1.2F5 cells were measured by a Caspase-3/CPP32 Colorimetric Protease Assay Kit, a Caspase-8/FLICE Colorimetric Protease Assay Kit, and a Caspase-9/Mch6 Colorimetric Protease Assay Kit (Medical and Biological Laboratories Co.), respectively. Briefly, the cells $(2 \times$ $10^{6}$ cells) in $100 \mathrm{~mm}$ dishes (Corning, Corning, NY, USA) were cultured with $10 \mathrm{ml}$ medium with the indicated concentrations of L-cell-conditioned medium and securioside B. After the indicated days, the adherent cells were harvested by scrapping with a rubber policeman. The cells were washed with PBS twice and lysed with Cell lysis buffer (Medical and Biological Laboratories Co.), and the supernatants were obtained after centrifuging at $10,000 \times g$ for 1 min. The protein concentrations of the cytosolic extracts were determined by Bradford protein assay (Pierce, Rockford, IL, USA) with bovine serum albumin as a standard. The caspase-3, caspase- 8 or caspase-9 activities of each $100 \mu \mathrm{g}$ protein extract were assayed by the measurement of DEVD-pNa, IETD-pNa, or LEHD-pNa cleavage, respectively.

\section{Western blotting of procaspases}

For the analysis of the processing of procaspase- 3 and procaspase-8, treated cells were lysed as already described and equal amounts of cytosolic extracts (10 $\mu \mathrm{g}$ protein/lane) were electrophoresed by sodium dodecyl sulfate-polyacrylamide gel electrophoresis (SDS-PAGE) using precast gels (NPG-520L; Atto Corp., Tokyo, Japan), and were transferred onto polyvinyldifluoride (PVDF) membranes (Bio-Rad, Hercules, CA, USA). Anti-caspase-3 and anti-caspase-8 antibodies were used at dilutions of 1:200, followed by incubation with anti-rabbit Ig-HRP. The signal was visualized with an ECL kit (Amersham, Arlington Heights, IL, USA).

\section{Western blotting of cytosolic cytochrome $c$}

The BAC1.2F5 cells $\left(2 \times 10^{6}\right.$ cells/dish $)$ were seeded onto culture dishes $(\phi=100 \mathrm{~mm})$ and treated with 
securioside B. Thereafter, the adherent cells were harvested as described, resuspended in ice cold preparation buffer-1 $[10 \mathrm{mM}$ Tris $-\mathrm{HCl}, \mathrm{pH} 7.5,0.3$ $\mathrm{M}$ sucrose, $10 \mu \mathrm{M}$ each of aprotinin, pepstatin, and leupeptin, and $1 \mathrm{mM}$ phenylmethylsulfonylfluoride), and homogenized using a Potter-type homogenizer (Weaton, Millville, NJ, USA). The post-mitochondria supernatants were obtained after centrifugation at $10,000 \times g$ for $60 \mathrm{~min}$ at $4^{\circ} \mathrm{C}$. The supernatants $(10$ $\mu \mathrm{g} /$ lane) were resolved by SDS-PAGE using precast gels (SPU-15S; Atto), and transferred onto PVDF membranes. The anti-cytochrome $c$ antibody was used at a dilution of 1:200, followed by incubation with anti-rabbit Ig-HRP. The signal was visualized with the ECL kit.

\section{Mitochondorial membrane potential}

The mitochondria membrane potential of treated cells was morphologically detected by a DePsipher ${ }^{\mathrm{TM}}$ kit (Trevigen, Inc., Gaithersburg, MD, USA). Briefly, the adherent cells on the Lab-Tek slide chambers were stained with $5,5^{\prime}, 6,6^{\prime}$,tetrachloro-1,1',3,3'-tetraethylbenzimidazolyl carbocyanin iodide (DePsipher), according to the manufacturer's instructions, in which it was indicated that the mitochondria would appear red due to the aggregation of DePsipher in healthy cells, whereas cells with disrupted mitochondria potential would appear green, under a fluorescence microscope.

\section{Results}

\section{Cytotoxicity of securioside B against BAC1.2F5 cells}

We previously showed that securiosides A and B (the structure of the securiosides is depicted in Fig. 1A) induced the apoptotic cell death of murine peritoneal macrophages in the presence of L-cell-conditioned medium or M-CSF in vitro. ${ }^{21}$ To further characterize the reaction, it was more suitable to use a cell line rather than heterogeneous macrophages collected from animals. Since the compounds did not exert very weak cytotoxicity for J.774.1 macrophage-like cells, which are able to grow without the support of the growth factor, we chose BAC1.2F5 cells, which require M-CSF or GM-CSF for survival or growth. ${ }^{22}$ In the present study, we used only securioside B, because the cytotoxic activity of securiosides $A$ and B towards macrophages or other cells was indistinguishable in our previous reports. ${ }^{20,21}$

Securioside B induced a marked decrease in the MTT-reducing activity of the BAC1.2F5 cells from 1 $\mu \mathrm{g} / \mathrm{ml}$ of the concentration, in the presence of L-cellconditioned medium (Fig. 1B): the dose-response relationship was quite similar to that of peritoneal macrophages. To examine whether the compound caused apoptosis of the cell type, the DNA breaks of the cells were examined morphologically by the TUNEL method. As shown in Fig. 2, DNA breaks were observed in many of the cells cultured with securioside B plus L-cell-conditioned medium for 3 days, whereas the cells cultured with the latter only were negative.

Comparison of the cytotoxicity of securiosides $B$ against BAC1.2F5 cells in the presence of L-cellconditioned medium, rM-CSF or rGM-CSF

We had previously obtained the preliminary data that securiosides A and B induced a decrease in the MTTreducing activity of peritoneal macrophages, only when the cells were cocultured with L-cell-conditioned medium or M-CSF: the macrophages cultured without any growth factor or with GM-CSF were much less sensitive to the compounds. ${ }^{20}$ However, the reduction in the MTT assay does not necessarily reflect cell death, as the inhibition of cell growth also causes the decrease. Therefore, we next examined
A
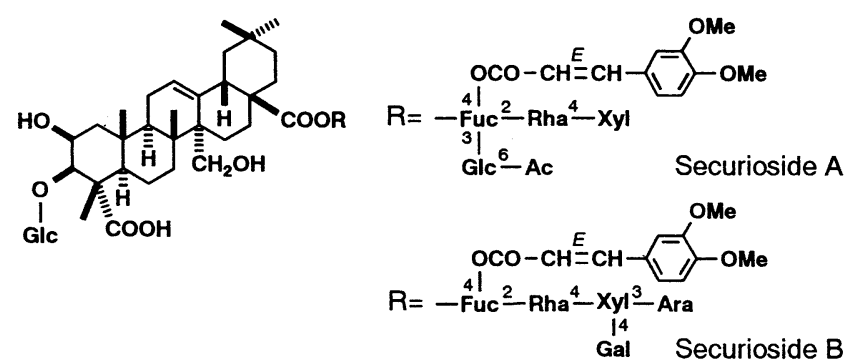

Securiosides $A$ and $B$
B

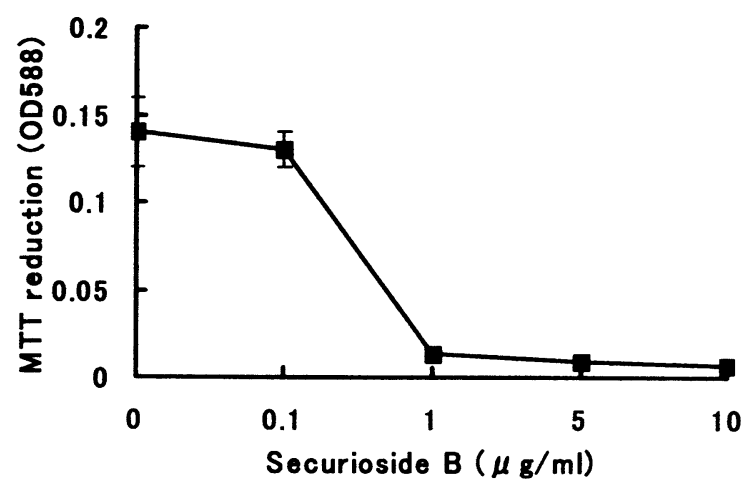

FIG. 1. (A) Structure of securiosides A and B. (B) Dose-response relationship of the cytotoxic effect of securioside B against the BAC1.2F5 cells. The BAC1.2F5 cells were cultured with $20 \%$ L-cell-conditioned medium and the indicated concentrations of securioside B. MTT-reducing activity was measured on day 3. Bars represent the standard deviation. 


\section{Phase contrast Fluorescence}

\section{$+\mathrm{L}-$ cell sup.}

+ L-cell sup.

+ Securioside B
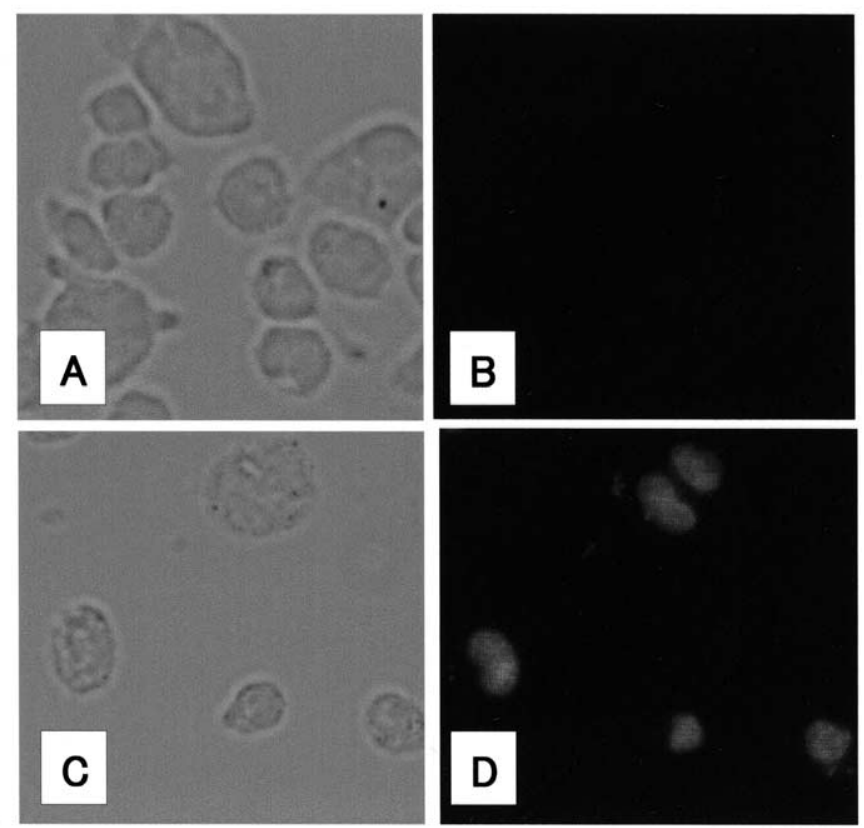

FIG. 2. Analysis of the DNA cleavage of the cultured BAC1.2F5 cells. The cells were cultured without (A, B) or with (C, D) $10 \mu \mathrm{g} /$ $\mathrm{ml}$ securioside $B$ in the presence of $20 \%$ L-cell-conditioned medium for 3 days. The cells were stained by the TUNEL method and observed with phase contrast microscopy (A, C). DNA breaks represented by fluorescein were detected by fluorescence microscopy (B, D).

precisely the effect of L-cell-conditioned medium, MCSF and GM-CSF, as co-factors for the cytotoxicity of securioside $\mathrm{B}$, comparing the results from the cellcounting assay and MTT assay.

As shown in Fig. 3A, the BAC1.2F5 cells did not proliferate without any growth factor(s). The addition of securioside $\mathrm{B}$ alone did not reduce the number of cells, without any growth factor, up to day 6. In contrast, the cells proliferated in the presence of Lcell-conditioned medium and securioside B caused marked a reduction in the number of these cells from day 3, and most cells were diminished on day 6: the compound induced cell death in this condition. On the other hand, securioside B completely suppressed the cell growth induced by rM-CSF, but did not reduce the initial cell number, even on day 6 (Fig. $3 \mathrm{~B}$ ), suggesting that the effect of securioside $\mathrm{B}$ in the presence of M-CSF is cytostatic, rather than cytocidal. Like M-CSF, rGM-CSF also induced the growth of the BAC1.2F5 cells $^{22}$ (Fig. 3C). Securoside B also suppressed the growth of the cells stimulated by GMCSF. However, the cell number at the start of the culture was scarcely decreased after 6 days of culture (Fig. 3C)

The dose-response effect of the growth factors was examined by MTT assay on day 3. The augmenting effect of L-cell-conditioned medium was observed at $4 \%$ concentration, and was increased to 20\% (Fig. 3D). Securioside B caused a marked decrease in MTT-reducing activity with 4\% L-cellconditioned medium, and almost complete abroga- tion was observed with the 20\% medium (Fig. 3D), suggesting extensive cell death occurred in this condition. rM-CSF induced marginal growth at 10 $\mathrm{ng} / \mathrm{ml}$, and the effect reached a plateau at $50 \mathrm{ng} / \mathrm{ml}$. The suppressive effect of securioside B was seen in the presence of $50 \mathrm{ng} / \mathrm{ml} \mathrm{M-CSF}$; however, it was not augmented by a higher amount $(250 \mathrm{ng} / \mathrm{ml})$ of $\mathrm{rM}$ CSF (Fig. 3E).

As shown in Fig. 3F, augmentation in the MTTreducing activity of rGM-CSF was seen even at $2 \mathrm{ng} /$ $\mathrm{ml}$. In spite of the potency of the growth-inducing activity of rGM-CSF, the factor itself induced a lesser augmentation in the MTT assay than M-CSF, even at higher concentrations. Securioside $\mathrm{B}$ induced a relatively small degree of decrease in MTT reduction in the cells cultured together with $2-250 \mathrm{ng} / \mathrm{ml} \mathrm{rGM-}$ CSF. Such a small augmenting effect of GM-CSF and a weak inhibitory effect of securioside B on GM-CSFtreated cells in the MTT assay may reflect that the cells cultured with GM-CSF were small and round in their morphology, while most of the cells with M-CSF were large and spread after 3 days (data not shown). Using peritoneal exudate macrophages we obtained similar results as described in Fig. 3A-E (data not shown).

To confirm the results that the effect of securioside $\mathrm{B}$ on cells cultured with M-CSF and/or GM-CSF is growth inhibitory rather than cytotoxic, and that the activity of L-cell-conditioned medium in supporting the cell death-inducing activity of securioside $\mathrm{B}$ is stronger than that of M-CSF and/or GM-CSF, we 

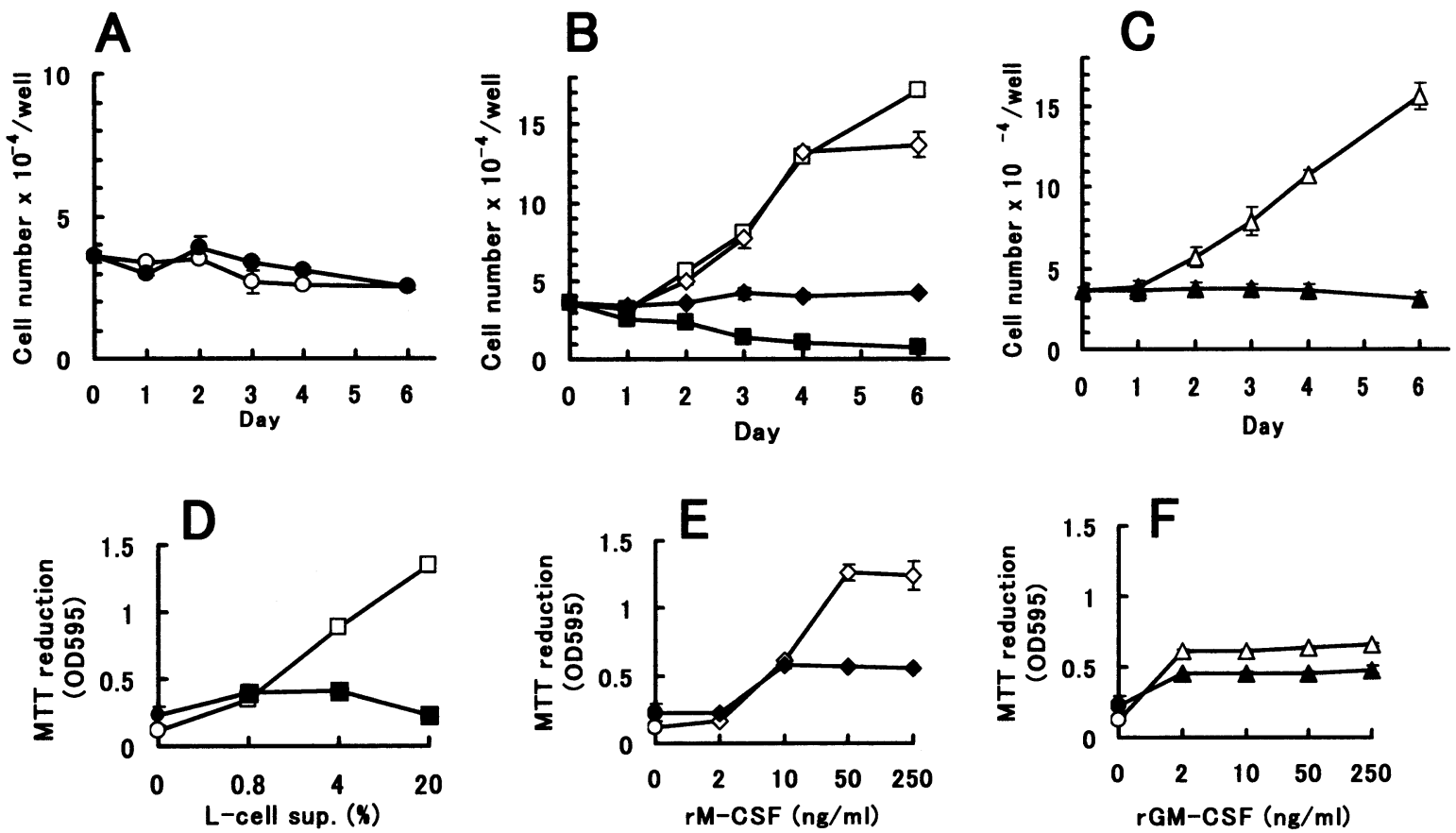

FIG. 3. Growth curves and MTT-reducing activities of the BAC1.2F5 cells cultured with securioside $B$ in the presence of L-cellconditioned medium, M-CSF or GM-CSF. (A) The BAC1.2F5 cells were cultured without $(O)$ or with $(0) 10 \mu \mathrm{g} / \mathrm{ml}$ securioside B in the absence of any macrophage growth-stimulating factor. The growth curves were estimated by cell counting. (B) and (C) Growth curves of the BAC1.2F5 cells cultured without (open symbols) or with (closed symbols) $10 \mu \mathrm{g} / \mathrm{ml}$ securioside $B$ in the presence of $20 \%$ L-cell-conditioned medium $(\square, \mathbf{\square}), 100 \mathrm{ng} / \mathrm{ml} \mathrm{rM-CSF}(\diamond, \diamond)$, or rGM-CSF $(\Delta, \Delta)$. Bars represent upper and lower values of duplicate estimations. (D-F) MTT-reducing activities of the cells treated without (open symbols) or with (closed symbols) $10 \mu \mathrm{g} / \mathrm{ml}$ securioside B in the presence of the indicated concentrations of L-cell-conditioned medium (D), rMCSF (E), or rGM-CSF (F). MTT-reducing activity was measured on day 3.

compared the release of the cytosolic enzyme, $\mathrm{LDH}$, from the treated BAC1.2F5 cells. As shown in Fig. 4, the majority of the total LDH activity was detected in the supernatant fraction after being cultured without any samples for 3 days, while the addition of securioside B slightly reduced LDH release. In contrast, $\mathrm{LDH}$ release was reduced to $20-40 \%$ of the total when the cells were cultured with L-cell-conditioned medium, M-CSF, and/or GM-CSF. These background values may have been a result of $\mathrm{LDH}$ release from a damaged population, which arose when the cells

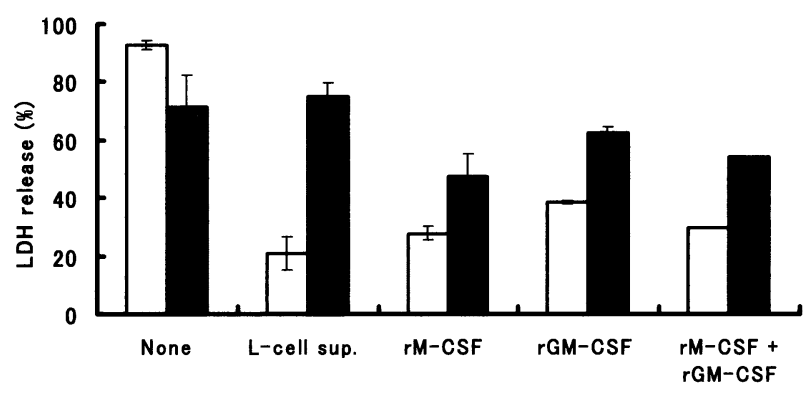

FIG. 4. Comparison of the cytolytic activity of securioside B against the BAC1.2F5 cells in the presence of L-cell-conditioned medium, M-CSF, and/or GM-CSF by LDH release assay. The BAC1.2F5 cells were cultured with $10 \mu \mathrm{g} / \mathrm{ml}$ securioside $B$ in the presence of L-cell-conditioned medium $(20 \%), 100 \mathrm{ng} / \mathrm{ml} \mathrm{rM}-\mathrm{CSF}, 100 \mathrm{ng} / \mathrm{ml} \mathrm{rGM}-\mathrm{CSF}$, or a mixture of rM-CSF and rGM-CSF (100 ng/ml of each) for 3 days. LDH release from the cells was described in Materials and methods. Bars represent the standard deviation. were scrapped with a rubber policeman in the initial cell preparation. The augmentation of LDH release by securioside $\mathrm{B}$ was the most potent with the addition of L-cell-conditioned medium, rather than with MCSF or GM-CSF. The induction of $\mathrm{LDH}$ release by securioside $\mathrm{B}$ was not augmented by the combination of M-CSF and GM-CSF.

\section{Caspase activation of BAC1.2F5 cells by securioside B plus L-cell-conditioned medium}

We next explored the intracellular pathway, in which securioside $\mathrm{B}$ induces $\mathrm{BAC1.2 \textrm {F } 5}$ apoptosis in the presence of L-cell-conditioned medium. It is well known that caspase-3 is known to be a pivotal effector caspase in the execution phase of apoptosis: the proteolytic activity of caspase- 3 is produced by the proteolytic cleavage of procaspase- 3 , which is activated by initiator caspases, caspase- 8 and caspase-9, located on the upstream of caspase- $3 .{ }^{25}$ Signal transduction of Fas or tumor necrosis factorreceptor-induced apoptosis reportedly requires the activation of caspase- $8{ }^{26}$ Another main pathway involves cytosolic Apaf-1 and cytochrome $c$ released from mitochondria, which cooperatively induce the activation of caspase-9. ${ }^{27-29}$ Therefore, to study the intracellular signal transduction of apoptosis induced by securioside $\mathrm{B}$, we first measured the enzymatic 
activity of caspase-3, caspase-8, and caspase- 9 of the BAC1.2F5 cells treated with the compound in the presence of L-cell-conditioned medium. As shown in Fig. 5A, the augmentation of caspase-3 activity by securioside $\mathrm{B}$ was observed on day 2 , and more clearly on day 3. Securioside $B$ also induced an increase in caspase-9 activity with a similar time course as caspase-3 (Fig. 5C). In sharp contrast, the compound did not augment caspase- 8 activity on day 2, nor even on day 3 (Fig. 5B).

To confirm the effect of securioside $B$ on the caspase activation of the BAC1.2F5 cells cultured in the presence of L-cell-conditioned medium, we next examined the processing of procaspase- 3 and procaspase- 8 by western blotting analysis. As shown in Fig. $6 \mathrm{~A}$, the content of procaspase- 3 in the cells was much decreased by the treatment of securioside $\mathrm{B}$, suggesting that it was cleaved to form the active enzyme in this condition. On the other hand, the compound did not reduce the amount of procaspase8. These results show good correlation with the changes in the enzymatic activities of these caspases.

\section{Effect of securioside $B$ on the mitochondria of BAC1.2F5 cells cultured with L-cell-conditioned medium}

Intracellular signal transduction of many apoptotic stimuli are known to involve a change in the permeability transition of the mitochondrial membrane and loss of mitochondrial membrane potential. ${ }^{30}$ Following these changes, several proapoptotic factors, such as cytochrome $c$, apoptosis-inducing factor (AIF), and endonuclease $G$, are released from mitochondria. ${ }^{31,32}$ Cytochrome $c$, together with Apaf1 , activates caspase- 9 , which in turn activate caspase3. ${ }^{27-29}$ Since caspase-9 was activated in the BAC1.2F5 cells treated with securioside $\mathrm{B}$ and L-cell-conditioned medium, we next examined whether cytochrome $c$ was released to the cytosol in these cells. As shown in Fig. 6B, cytochrome $c$ was detected in the cytosolic fraction of the cells cultured with the compound in the presence of L-cell-conditioned medium, suggesting that the stimuli of the compound caused cytochrome $c$ release from the mitochondria.

We next performed a morphological analysis of mitochondrial membrane potential using a fluorescent probe, DePsipher. As shown in Fig. 7, loss of the membrane potential was observed in most of the cells cultured with securioside B plus L-cell-conditioned medium.

\section{Discussion}

We had previously reported that securiosides induce macrophage-oriented growth inhibition and apoptosis, since these compounds need a 10-fold to 100-fold higher concentration to exert cytotoxicity against tumor cell lines. ${ }^{20}$ Moreover, securiosides acted on macrophages only when the cells were cultured with L-cell-conditioned medium. In the present study, we characterized the action of the compounds towards BAC1.2F5 cells in the absence or presence of L-cell-

\section{A Caspase-3 activity}

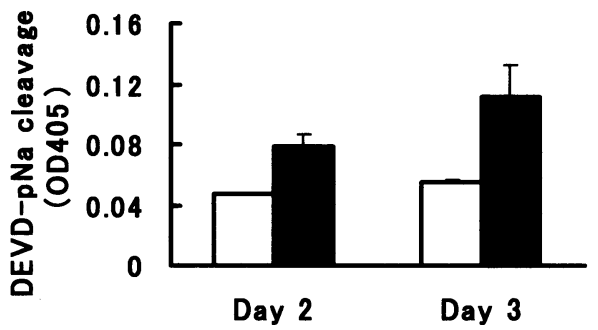

B Caspase-8 activity

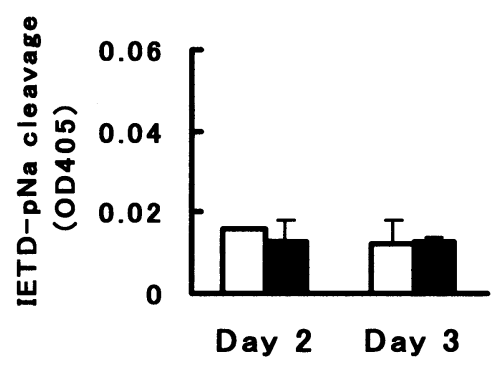

C Caspase-9 activity

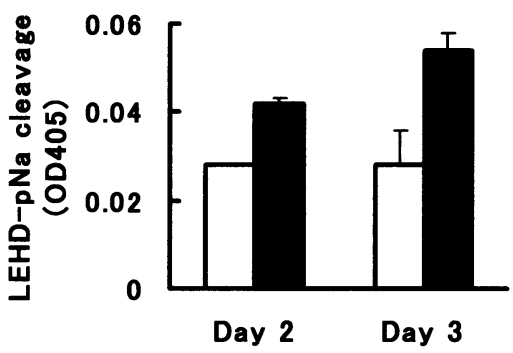

FIG. 5. Caspase-3, caspase-8, or caspase- 9 activities of the BAC1.2F5 cells cultured with securioside B. The BAC1.2F5 cells were cultured without (white bars) or with $10 \mu \mathrm{g} / \mathrm{ml}$ securioside B (black bars) in the presence of L-cell-conditioned medium (20\%). On the indicated days, the cells were harvested, and caspase- 3 activity (A), caspase-8 activity (B), and caspase-9 activity (C) were measured as described in Materials and methods. Bars represent upper and lower values of duplicate estimations. 


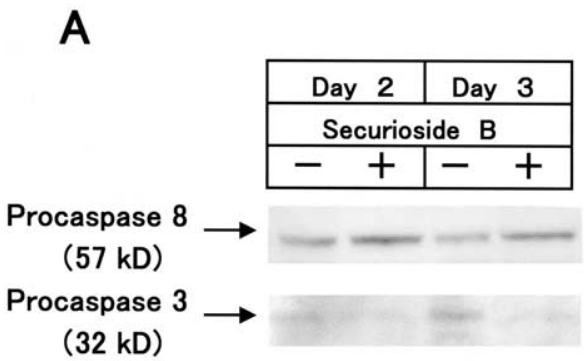

B

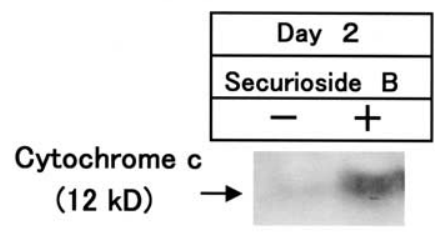

FIG. 6. Western blotting analysis of the processing of procaspases and cytosolic cytochrome $c$. The BAC1.2F5 cells were harvested on the indicated days, and the processing of procaspase-8 and procaspase-3 (A) or cytosolic cytochrome $c$ (B) were analyzed.
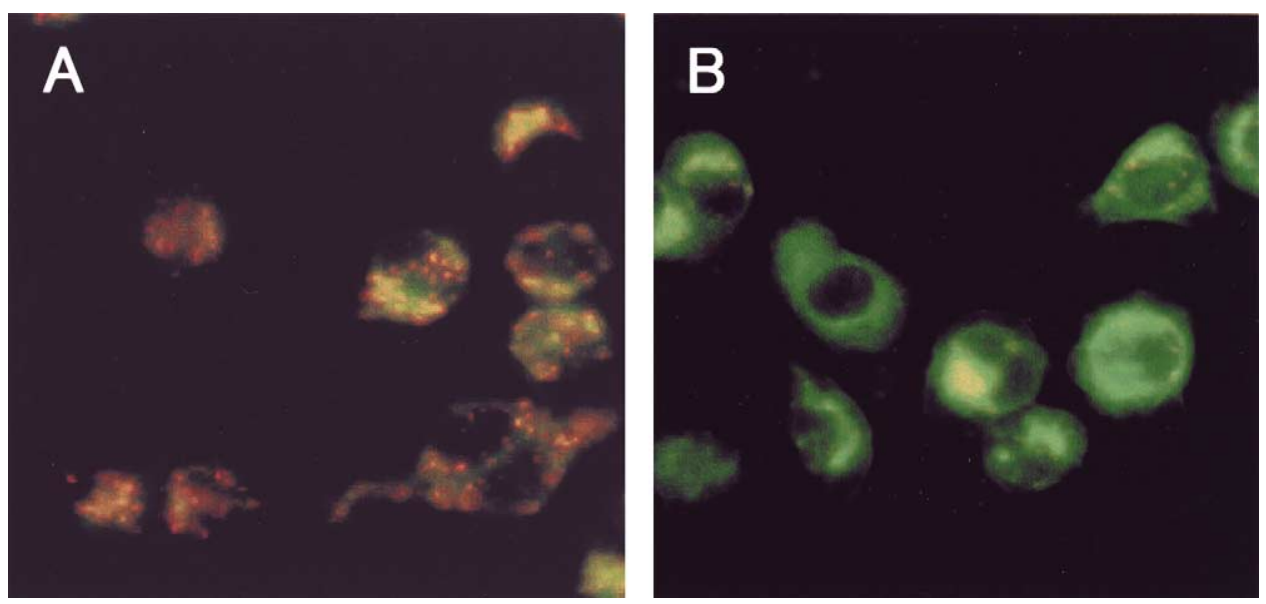

FIG. 7. Analysis of mitochondorial membrane potential of the BAC1.2F5 cells cultured with securioside $\mathrm{B}$. The cells were cultured without (A) or with (B) $10 \mu \mathrm{g} / \mathrm{ml}$ securioside B in the presence of L-cell-conditioned medium (20\%). On day 2, the cells were stained with DePsipher. The intact mitochondria appear red, whereas mitochondria with disrupted potential appear green.

conditioned medium, M-CSF, or GM-CSF. It was interesting that when BAC1.2F5 cells were cultured with M-CSF and/or GM-CSF, the compound induced growth inhibition rather than cell death induction. Macrophage growth induced by these factors might be related to the pathological process of many diseases. For example, M-CSF was reportedly expressed in atherosclerotic lesions, and the growth of macrophage-derived foam cells was thought to be important in the development of these lesions. ${ }^{7,8}$ Compounds that have securioside B-like activity might inhibit macrophage growth without attenuating their viability in such pathological lesions.

The data that showed that securioside $\mathrm{B}$ induced apoptosis in the presence of L-cell-conditioned medium suggest that $\mathrm{L}$ cells might produce additional factors that sustain the apoptosis-inducing activity of securioside B, besides M-CSF. It is considerable that the growth or functional states of macrophages and fibroblasts are regulated by each other. For example, it was recently reported that normal dermal fibroblasts express a monocyte-specific chemokine, BRAK, which may be involved in the generation of tissue macrophages. ${ }^{33}$ Since it has not been reported whether fibroblast factors contribute to the induction of macrophage apoptosis, it is important to examine whether not only L-cell fibrosarcoma cells, but also normal fibroblasts, produce the factors that support the apoptosis-inducing activity of securioside B. To understand the physiological mechanism controlling the death of macrophages, the nature of the factors produced by L cells is the next important subject to be elucidated.

A possible mechanism for the apoptosis induction by securioside $\mathrm{B}$ is that the compound with L-cellconditioned medium stimulates the BAC1.2F5 cells to produce cell death-inducing cytokines, such as tumor necrosis factor or Fas ligand, in an autocrine or a paracrine fashion, because Fas-Fas ligand interactions reportedly induced the apoptosis of human monocytes and macrophages. ${ }^{34,35}$ However, this is not probable, since caspase- 8 of the cells, which is located downstream of Fas or tumor necrosis factorreceptor stimulation, was not activated by securioside B plus L-cell-conditioned medium, but the activation of caspase-3 and caspase-9 was observed.

Many apoptosis-inducing stimuli are known to engage the mitochondrial (intrinsic) pathway, in which cytochrome $c$ and multiple proapoptotic factors are released from the mitochondria. ${ }^{26,30,31}$ Cytochrome $c$ reportedly binds Apaf- 1 in cooperation with (deoxy)adenosine triphosphate in the 
cytosol to be assembled into apoptosome, which activates effector caspases, such as caspase- $3 .{ }^{26-28}$ Securioside B induced the loss of mitochondrial membrane potential, cytochrome $c$ release into the cytosols, and caspase-9 activation of BAC1.2F5 cells cultured with L-cell-conditioned medium, suggesting that the compound induced apotosis through the mitochondrial pathway. In addition to cytochrome $c$, multiple proapoptotic or antiapoptotic factors are released from mitochondria. Among these, AIF and endonuclease $\mathrm{G}$ reportedly induce apoptosis without the mediation of caspases. ${ }^{30,31}$ We observed that apoptosis induction by securioside-B plus L-cellconditioned medium was not inhibited by a pancaspase inhibitor, Z-VAD-fmk (data not shown), suggesting that the postmitochondorial mechanism included not only caspase-9, caspase-3 and other caspases, but also caspase-independent molecules, such as AIF. Additional experiments are needed to uncover the mitochondrial factors that are essential for the execution of apoptosis.

The upstream events that induce a loss of mitochondrial membrane potential are still unknown. One possibility is that securioside $\mathrm{B}$ inhibits the intracellular signal transduction pathway of M-CSF and, in concert with this inhibition, factors other than $\mathrm{M}-\mathrm{CSF}$ in L-cell-conditioned medium might produce additive signals to affect the mitochondria. Therefore, it is important to elucidate the point of action of the compound in the inhibition of the growth-inducing activity of M-CSF. It was recently reported that the addition of a ganglioside (GD3) to intact cells induced apoptosis, and GD3 directly induced cytochrome $c$ release from isolated mitochondria. ${ }^{36}$ Since securioside $\mathrm{B}$ is an amphipatic molecule, possibly having micelle formation characters as gangliosides, an alternative possibility is that securioside B was incorporated by the macrophages and recruited into the mitochondrial membrane, which resulted in inducing mitochondrial permeability transition. In our preliminary result, $100 \mu \mathrm{g} / \mathrm{ml}$ securioside B induced cytochrome $c$ release from the mitochondria isolated from the BAC1.2F5 cells (data not shown). M-CSF or the other factors in L-cell-conditioned medium might augment securioside $\mathrm{B}$ incorporation by macrophages.

The mechanism controlling the life span of inflammatory macrophages in vivo is obscure. We recently reported that enterolosaponins $\mathrm{A}$ and $\mathrm{B}$, novel triterpene saponins, also exerted macrophage-oriented cytotoxicity. ${ }^{37}$ It is possible that securiosides, or other saponins, mimic unidentified physiological molecules having regulatory activity for macrophage growth or survival, which exist endogenously or are derived from microorganisms. The results described here might provide clues to exploring pharmacological manipulations, as well as the physiological control mechanism of the life span or the growth state of peripheral macrophages.

ACKNOWLEDGEMENT. The authors thank Dr E. Richard Stanley for kindly providing BAC1.2F5 cells.

\section{References}

1. Adams DO, Hamilton TA. Macrophages as destructive cells in host defense. In: Gallin JI, Golstein IM, Snyderman R, eds. Inflammation: Basic Principles and Clinical Correlates, New York: Raven Press, 1992. $637-662$.

2. Auger MJ, Ross JA. The biology of macrophage. In: Lewis CE, McGee JO'D, eds. The Macrophage, Oxford: Oxford University Press, 1992: 157

3. Evans R, Cullen RT. In situ proliferation of intratumor macrophages. $J$ Leuk Biol 1984; 35: 561-572.

4. Stewart CC. Local proliferation of mononuclear phagocytes in tumors. $J$ Reticuloendothel Soc 1983; 34: 23-27.

5. Stary HC, Malinow MR. Ultrastructure of experimental coronary artery atherosclerosis in cynomolgus macrophages: a comparison with the lesions of other primates. Atherosclerosis 1982; 48: 95-100.

6. Villaschi LG, Spagnoli LG. Autoradiographic and ultrastructural studies on the human fibro-atheromatous plaque. Atherosclerosis 1983; 48: $95-$ 100.

7. Rosenfeld ME, Ross R. Macrophage and smooth muscle cell proliferation in atherosclerotic lesions of WHHL and comparably hypercholesterolemic fat-fed rabbits. Arteriosclerosis 1990; 10: 680-687.

8. Gordon D, Reidy MA, Benditt EP, Schwart SM. Cell proliferation in human coronary arteries. Proc Natl Acad Sci USA 1990; 87: 4600-4604.

9. Bitterman PB, Saltzman LE, Adelberg S, Ferrans VJ, Crystal RG. Alveolar macrophage replication. One mechanism for the expansion of the mononuclear phagocyte population in the chronically inflamed lung. $J$ Clin Invest 1984; 74: 460-469.

10. Goto M, Matsuno K, Yamaguchi Y, Ezaki T, Ogawa M. Proliferation kinetics of macrophage subpopulations in a rat experimental pancreatitis model. Arch Histol Cytol 1993; 56: 75-82.

11. Stanley ER, Chen DM, Lin HS. Induction of macrophage production and proliferation by a purified colony stimulating factor. Nature 1978; 274: $168-170$.

12. Chen BD-M, Clark CR, Chou TH. Granulocyte/macrophage colonystimulating factor stimulates monocyte and tissue macrophage proliferation and enhances their responsiveness to macrophage colony-stimulating factor. Blood 1988; 71: 997-1002.

13. Chodakewits JA, Kupper TS, Coleman DL. Keratinocyte-derived granulocyte/macrophage colony-stimulating factor induces DNA synthesis of peritoneal macrophages. J Immunol 1988; 140: 832-836.

14. Yui S, Yamazaki M. Induction of macrophage growth by effete cells. $J$ Leuk Biol 1986; 39: 489-497.

15. Yui S, Sasaki T, Miyazaki A, Horiuchi S, Yamazaki M. Induction of murine macrophage growth by modified LDLs. Arterioscler Thromb 1993; 13: 331-337.

16. Yui $S$, Sasaki $T$, Araki N, Horiuchi $S$, Yamazaki $M$. Induction of macrophage growth by advanced end products of the Maillard reaction. J Immunol 1994; 152: 1943-1949.

17. Sasaki T, Horiuchi S, Yamazaki M, Yui S. Stimulation of macrophage DNA synthesis by polyanionic substances through binding to the macrophage scavenger receptor. Biol Pharm Bull 1996; 19: 449-455.

18. Lin EY, Nguyen AV, Russell RG, Pollard JW. Colony-stimulating factor 1 promotes progression of mammary tumors to malignancy. J Exp Med 2001; 193: 727-739.

19. Rooijen NV, Sanders A. Elimination, blocking, and activation of macrophages: three of a kind? J Leuk Biol 1997; 62: 702-709.

20. Kuroda M, Mimaki Y, Sashida Y, Kitahara M, Yamazaki M, Yui S. Securiosides A and B, novel acylated triterpene bisdesmosides with selective cytotoxic activity against M-CSF-stimulated macrophages. Bioorg Med Chem Lett 2001; 11: 371-374.

21. Yui S, Ubukata K, Hodono K, et al. Macrophage-oriented cytotoxic activity of novel triterpene saponins extracted from roots of Securidaca inappendiculata. Int Immunopharm 2001; 1: 1989-2000.

22. Morgan C, Pollard JW, Stanley ER. Isolation and characterization of a cloned growth factor dependent macrophage cell line, BAC1.2F5. J Cell Physiol 1987; 130: 420-427

23. Mosmann T. Rapid colorimetric assay for cellular growth and survival: application to proliferation and cytotoxicity assays. J Immunol Methods 1983; 65: $55-63$

24. Gavrieli Y, Sherman Y, Ben-Sasson SA. Identification of programmed cell death in situ via specific labeling of nuclear DNA fragmentation. $J$ Cell Biol 1992; 119: 493-501.

25. Strasser A, O'Connor L, Dixit VM. Apoptosis signalling. Annu Rev Biochem 2000; 69: 217-245. 
26. Boldin MP, Goncharov TM, Golsev YV, Wallach D. Involvement of $\mathrm{MACH}$, a novel MORT1/FADD-interacting protease, in Fas/APO- and TNF receptor-induced cell death. Cell 1996; 85: 803-815.

27. Zou H, Li Y, Liu X, Wang X. An APAF-1-cytochrome c multimeric complex is a functional apoptosome that activates procaspase-9. J Biol Chem 1999; 274: 11549-11556.

28. Hu Y, Bebedict MA, Ding L, Nunez G. Role of cytochrome c and dATP/ ATP hydrolysis in APAF-1-mediated caspase-9 activation and apoptosis. EMBO J 1999; 18: 3586-3595.

29. Thornberry NA, Lazebnik Y. Caspases: enemies within. Science 1998; 281: $1312-1316$.

30. Susin SA, Zamzami N, Kroemer G. Mitochondria as regulators of apoptosis: doubt no more. Biochim Biophys Acta 1998; 1366: 151-165.

31. Joza N, Susin SA, Daugas E, et al. Essential role of the mitochondrial apoptosis-inducing factor in programmed cell death. Nature 2001; $\mathbf{4 1 0}$ $549-554$.

32. Li LY, Luo X, Wang X. Endonuclease G is an apoptotic Dnase when released from mitochondria. Nature 2001; 412: 95-99.

33. Kurth I, Willimann K, Schaeri P, Hunziker T, Clark-Lewis I, Moser B. Monocyte selectivity and tissue localization suggests a role for breast and kidney-expressed chemokine (BRAK) in macrophage development. $J$ Exp Med 2001; 194: 855-861

34. Kiener PA, Davis PM, Starling GC, et al. Differential induction of apoptosis by Fas-Fas ligand interactions in human monocytes and macrophages. J Exp Med 1997; 185: 1511-1516.

35. Borges VM, Falcão $\mathrm{H}$, Leite-Júnior $\mathrm{JH}$, et al. Fas ligand triggers pulmonary silicosis. J Exp Med 2001; 194: 155-163.

36. Maria RD, Lenti L, Malisan F, et al. Requirement for GD3 ganglioside in CD95- and ceramide-induced apoptosis. Science 1997; 277: 1652-1655.

37. Mimaki Y, Harada $\mathrm{H}$, Sakuma $\mathrm{C}$ e et al Enterolosaponins A and B, novel triterpene bisdesmosides from Enterolobium contorisiliquum, and evaluation for their macrophage-oriented cytotoxic activity. Bioorg Med Chem Lett 2003; 13: 623-627.

Received 24 March 2003

Accepted 7 April 2003 


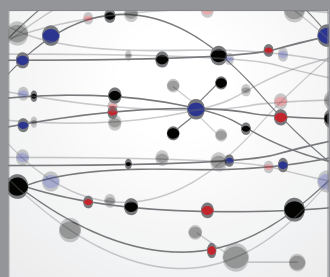

The Scientific World Journal
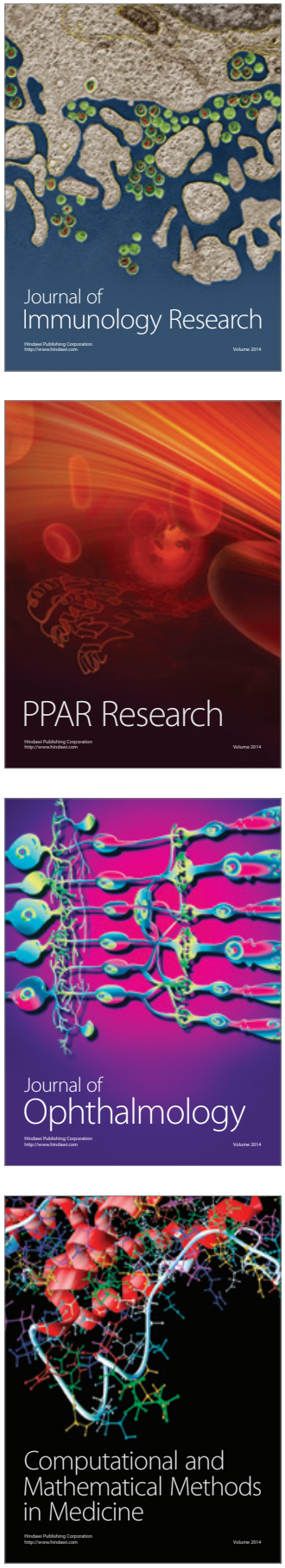

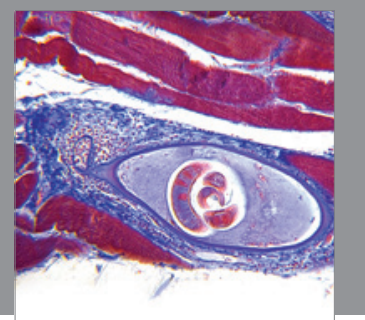

Gastroenterology

Research and Practice
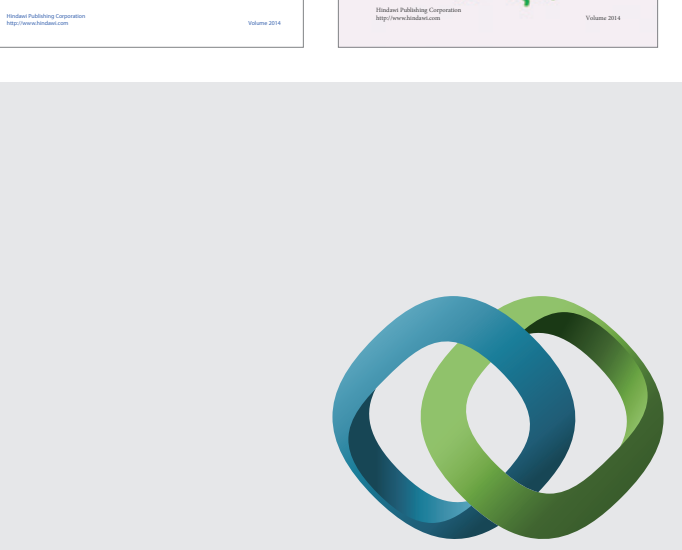

\section{Hindawi}

Submit your manuscripts at

http://www.hindawi.com
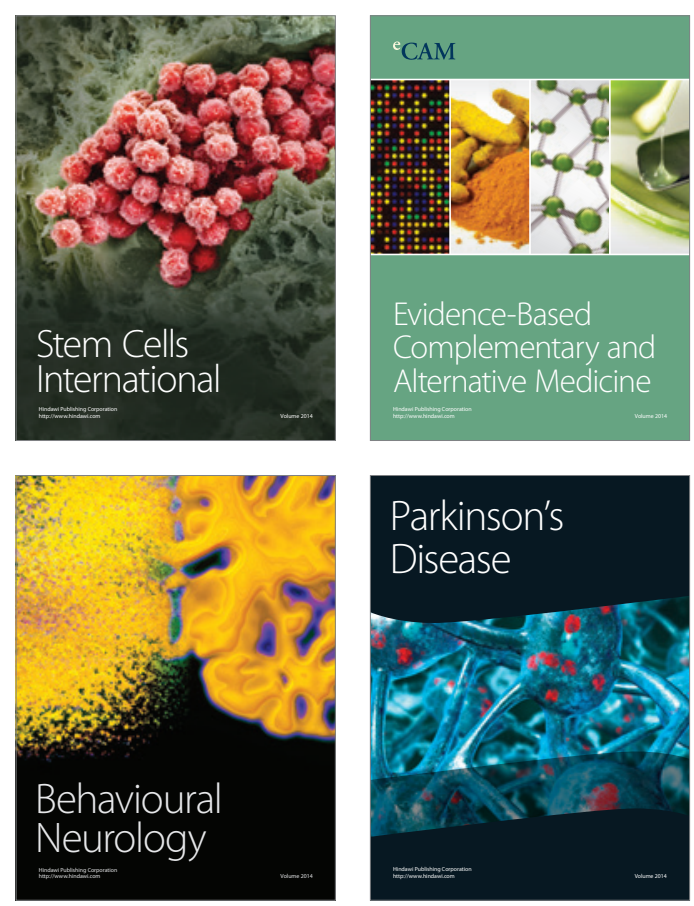

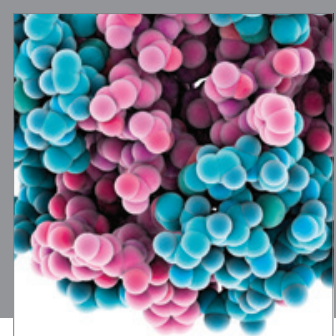

Journal of
Diabetes Research

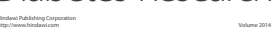

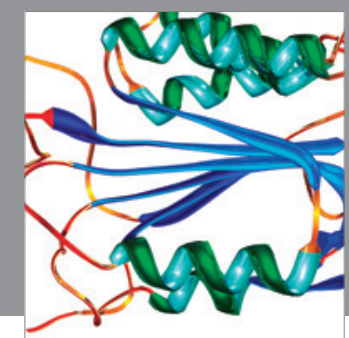

Disease Markers
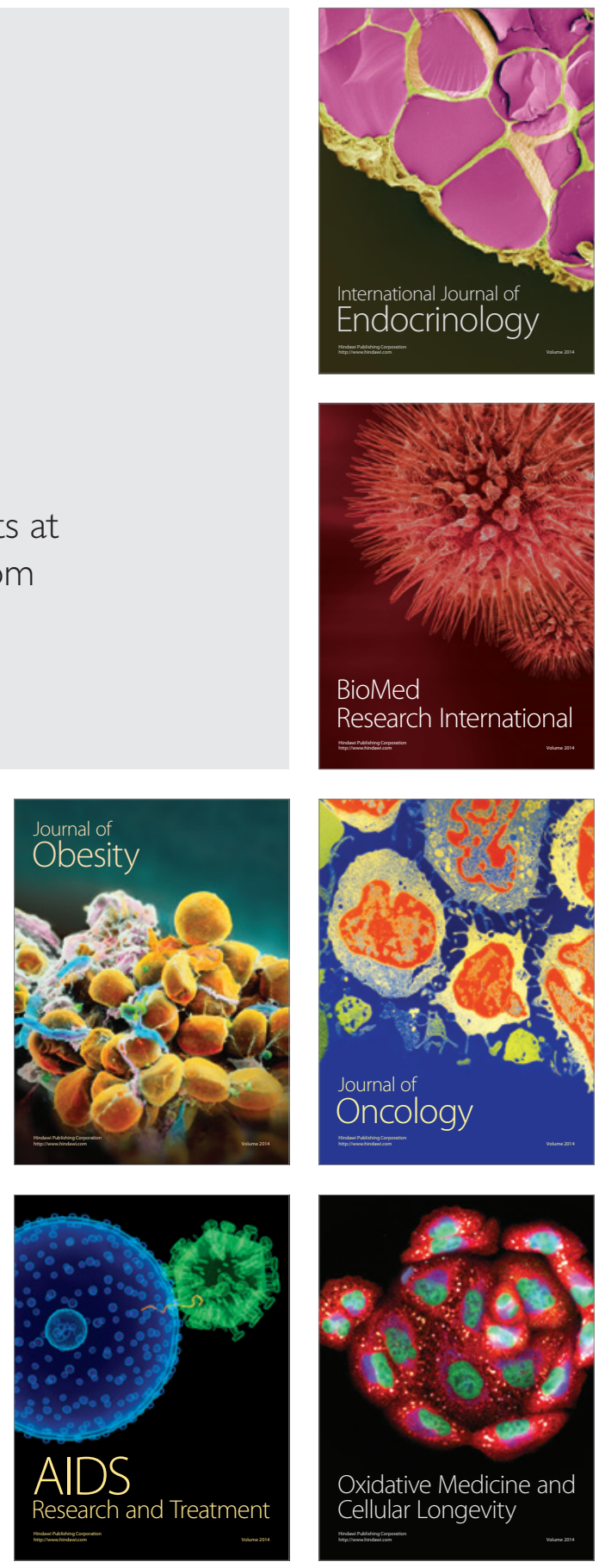